\title{
High energy beam impact tests on a LHC tertiary collimator at the CERN high-radiation to materials facility
}

\author{
Marija Cauchi* \\ CERN, Geneva, Switzerland, and University of Malta, Msida, Malta
}

\author{
O. Aberle, R. W. Assmann, ${ }^{\dagger}$ A. Bertarelli, F. Carra, K. Cornelis, A. Dallocchio, D. Deboy, \\ L. Lari, S. Redaelli, A. Rossi, and B. Salvachua \\ CERN, Geneva, Switzerland
}

P. Mollicone, and N. Sammut

University of Malta, Msida, Malta

(Received 17 September 2013; published 24 February 2014)

\begin{abstract}
The correct functioning of a collimation system is crucial to safely operate highly energetic particle accelerators, such as the Large Hadron Collider (LHC). The requirements to handle high intensity beams can be demanding. In this respect, investigating the consequences of LHC particle beams hitting tertiary collimators (TCTs) in the experimental regions is a fundamental issue for machine protection. An experimental test was designed to investigate the robustness and effects of beam accidents on a fully assembled collimator, based on accident scenarios in the LHC. This experiment, carried out at the CERN High-Radiation to Materials (HiRadMat) facility, involved $440 \mathrm{GeV}$ proton beam impacts of different intensities on the jaws of a horizontal TCT. This paper presents the experimental setup and the preliminary results obtained, together with some first outcomes from visual inspection and a comparison of such results with numerical simulations.
\end{abstract}

DOI: 10.1103/PhysRevSTAB.17.021004

PACS numbers: 29.27.-a, 07.05.Tp, 79.20.Ap

\section{INTRODUCTION}

The introduction of new, extremely energetic particle accelerators, such as the LHC [1], has established the need for advanced beam cleaning and protection systems in order to be able to safely increase the energy and intensity of particle beams to unprecedented levels [2]. The main purpose of the LHC collimation system [3] is, in fact, to ensure beam halo cleaning and machine protection.

The LHC collimation system consists of 108 collimators, of which 100 are movable collimators, placed in seven out of eight LHC interaction regions as well as in the transfer lines [4]. Collimators can be installed in vertical, horizontal, and skew configurations in order to ensure complete cleaning all around the particle beam axis. The collimation system implements a multistage beam cleaning process (Fig. 1) in order to remove particles that would otherwise be lost in the machine, and thus ensures efficient $(>99 \%)$ cleaning of the beam halo during the full LHC beam cycle. Being in close proximity to the beam, the collimator jaws

\footnotetext{
*marija.cauchi@cern.ch

Present address: DESY, Germany.

${ }^{\ddagger}$ Also at IFIC (CSIC-UV), Valencia, Spain.
}

Published by the American Physical Society under the terms of the Creative Commons Attribution 3.0 License. Further distribution of this work must maintain attribution to the author(s) and the published article's title, journal citation, and DOI. are continuously exposed to direct interaction with high energy particles. In fact, in normal working conditions, a steady state thermal load is deposited on the collimator jaws as the latter continuously interact with particles belonging to the external beam halo. In particular, continuous beam losses from the halo occur at the primary collimators, with the scattered debris of these low energy density protons subsequently being captured at the secondary and tertiary collimators, respectively.

Moreover, in the event of an accident scenario, with nominal beam conditions (362 MJ at $7 \mathrm{TeV}$ ), the collimators are strategically positioned in order to be hit by the primary beam particles, thus serving as a protection for

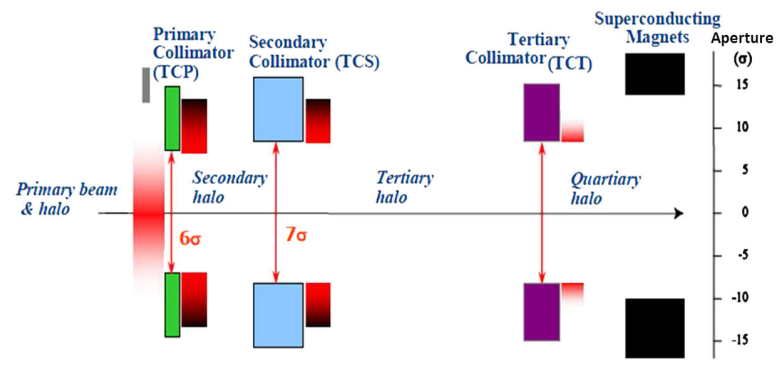

FIG. 1. Qualitative schematic diagram of the LHC multistage collimation system where the primary collimator jaws are positioned closest to the beam while the jaws of the secondary and tertiary collimators are retracted further away from the beam. 
other critical structures such as the superconducting (SC) magnets [5]. Most of the beam is expected to be safely disposed of by the beam dump system in IP6, but other collimators around the ring [in particular the tertiary collimators (TCTs) that are close to the experiments] act as a last line of defense for passive machine protection.

In the worst accident case corresponding to an asynchronous trigger of the beam dumping system [6], a spontaneous misfiring of one of the horizontal extraction kicker magnets causes a trigger outside the abort gap. This causes some bunches to be kicked at an angle that is smaller than the nominal kick, and consequently they circulate for one turn before being kicked out. In this scenario, one or more high energy density bunches might directly impact on a collimator with possible serious consequences. While the carbon collimators [primary collimators (TCPs) and secondary collimators (TCSs)] in the warm cleaning insertions are designed to withstand such a worst case scenario without permanent damage, this is not the case for metal-based collimators like the TCTs in the experimental regions that protect the SC triplet magnets [7]. Even though the machine configurations [8] are chosen to minimize this risk in a way that it can only occur in case several unlikely combined failures occur at the same time [9], it is important to understand the implications of the catastrophic event on a TCT.

A dedicated beam experiment (HRMT-09) was set up at the HiRadMat facility [10] in order to obtain a thorough integral assessment of beam accident scenarios involving a complete tertiary collimator. The main aim of the experiment was to address the effects of an asynchronous beam dump considering a relevant nominal $7 \mathrm{TeV}$ case, as well as to benchmark simulations for the $\mathrm{LHC}$ cases at $5 \mathrm{TeV}$ which have been considered during the LHC run 1 [7]. A complementary dedicated experiment (HRMT-14) [11] was also carried out at the same facility in order to address novel materials of interest for collimators like dispersionstrengthened copper, molybdenum, and metal-diamond/ metal-graphite composites.

This paper gives an overview of HRMT-09. It first presents the experimental setup, giving a description of the TCT design and the installation layout. This is followed by an overview of the tests performed and the main beam test results including some first outcomes from visual inspection. Finally, a comparison of these experimental results with numerical simulations is discussed.

\section{EXPERIMENTAL SETUP}

\section{A. Tertiary collimator design}

The design of LHC collimators [12] must comply with very demanding specifications resulting from the highly energetic beam handled in the LHC. The TCT (Fig. 2) consists of two jaws contained in a vacuum tank. Two stepping motors per jaw allow independent adjustment of

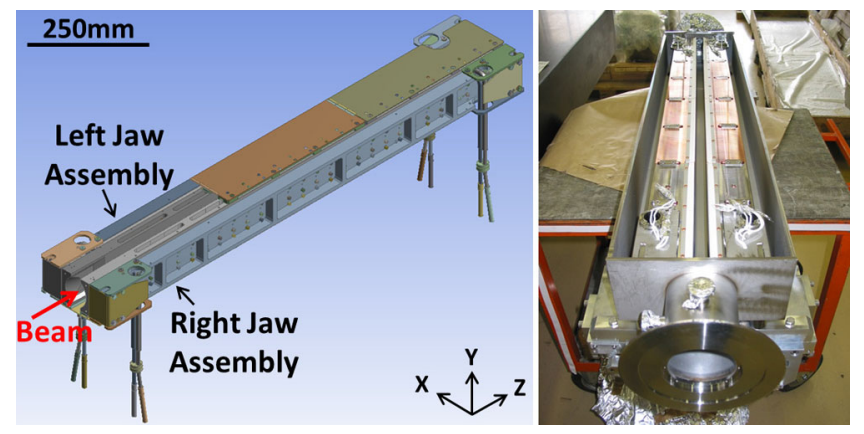

FIG. 2. A 3D model (left picture) and a top view (right picture) of a horizontal tertiary collimator (TCT).

jaw tilt and jaw position relative to the beam center. Transverse movements of the whole collimator tank are possible to determine the jaw surface that sees the beam. During the experiment, the jaws were moved remotely via a control application.

A detailed view of the jaw assembly is shown in Fig. 3. Each jaw has an active length of $1 \mathrm{~m}$ (total length $=1.2 \mathrm{~m}$ ) that consists of five inserts made of a tungsten heavy alloy, known commercially as Inermet $180(95 \% \mathrm{~W}-3.5 \% \mathrm{Ni}-1.5 \%$ $\mathrm{Cu}$ ). The blocks are mounted into a copper housing and fixed with screws to the assembly. The water cooling pipes are an integral part of the collimator structure and were connected to the external cooling circuit provided in the HiRadMat experimental area. The total flow of the cooling water was adjusted according to settings for standard LHC collimators (25 l/ $\mathrm{min})$.

\section{B. Installation layout and measurement sensors}

The collimator robustness experiment (HRMT-09) was carried out in August 2012 at the CERN HiRadMat test facility, which is located in the TNC tunnel in the Super

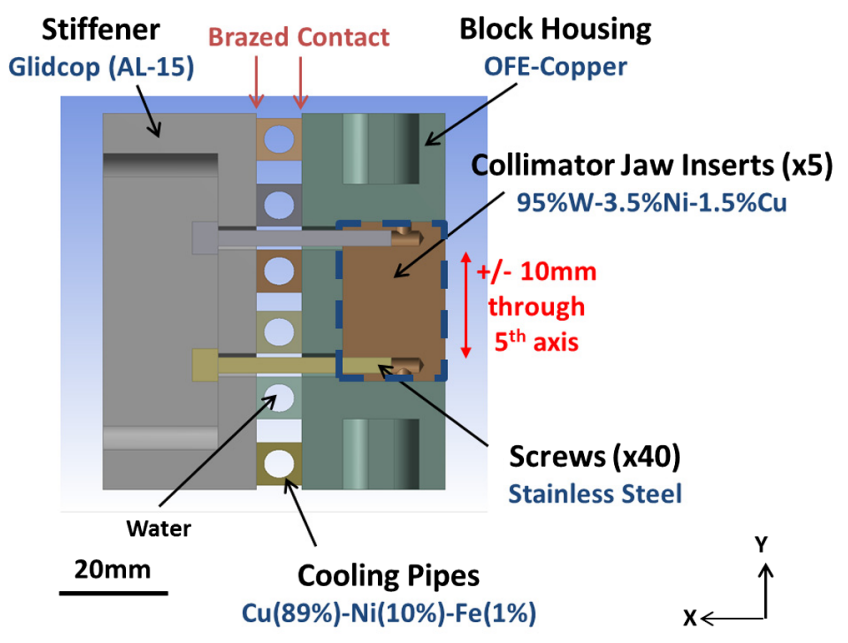

FIG. 3. Detailed cross section in the $x-y$ plane of the TCT left jaw assembly. 
TABLE I. HiRadMat beam design parameters for protons.

\begin{tabular}{lc}
\hline \hline Parameters & Protons \\
\hline Energy & $440 \mathrm{GeV}$ \\
Bunch intensity (max) & $1.7 \times 10^{11}$ \\
Number of bunches (max) & 288 \\
Pulse intensity (max) & $4.9 \times 10^{13}$ \\
Pulse energy (max) & $3.4 \mathrm{MJ}$ \\
Bunch length & $11.24 \mathrm{~cm}$ \\
Bunch spacing & $2.5 \div 150 \mathrm{~ns}$ \\
Pulse length (max) & $7.2 \mu \mathrm{s}$ \\
Transverse normalized emittance $(1 \sigma)$ & $2 \div 4 \mu \mathrm{m}$ \\
\hline \hline
\end{tabular}

Proton Synchrotron (SPS) BA7 area. HiRadMat was designed and recently commissioned to provide highintensity pulsed beams to an irradiated test area where full assemblies can be tested. The facility uses a LHC-type particle beam that is extracted from the CERN SPS and delivered to HiRadMat via two transfer lines, TT60 and TT66. Both protons and ions can be used for tests within the facility.

The collimator robustness tests were run at different intensities using $440 \mathrm{GeV}$ proton beams. Table I gives the beam design parameters for proton operation. It should be noted that for a given emittance, the size of the proton beam is a function of the optics, which depend on the quadrupole settings and on the longitudinal position in the region of the experimental area. The beam line is capable to provide beam radii between $\sigma=0.1 \mathrm{~mm}$ and $\sigma=2.0 \mathrm{~mm}$ at the different focal point positions of the experimental area ( $\sigma$ values corresponding to the nominal emittance). Moreover, different beam spot sizes are then achievable at the different test stands as further explained in [13]. An installation layout sketch is shown in Fig. 4 and more details on the beam line can be found in [10].

A fully operational, series production horizontal tertiary collimator was mounted on a support frame and the fully assembled table was lowered to the experimental area. The choice of a horizontal collimator was due to the fact that asynchronous beam dump accidents involve only horizontal collimators as the kicker magnets can only act on the horizontal plane. The collimator was installed a few meters upstream of a beam dump (Fig. 4) and its response to the different beam impacts was captured, relying on embarked instrumentation.

The collimator prototype was equipped with additional instrumentation compared to a standard LHC TCT. Standard LHC collimator equipment includes two stepper motors per jaw, position sensors as well as temperature sensors. A vacuum pump with external power connection, a fifth stepper motor allowing vertical movements of the whole collimator tank (20 mm full stroke) and some additional temperature and pressure sensors on various components of the collimator were also installed, specifically for the HiRadMat experiment. All sensor readouts

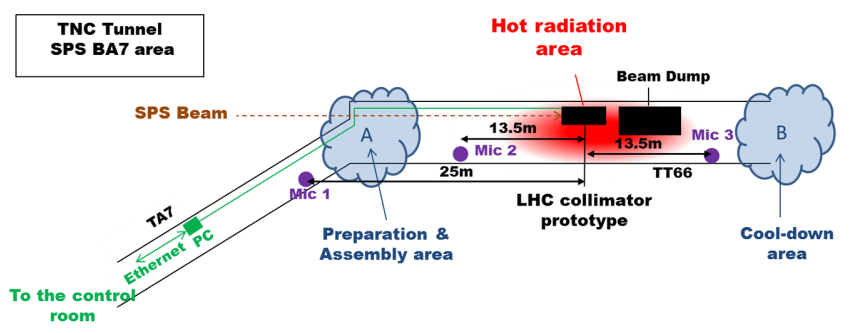

FIG. 4. Installation layout for the collimator at TT66.

were monitored online and stored for analyses. The main technical specifications of the various sensors and other equipment are listed in Table II.

To benchmark simulations, one of the most important physical entities to be acquired was the temperature developed within the jaws of the collimator. The four jaw temperature sensors were attached to the back of the copper housing in the same way as in a standard TCT unit (Fig. 5). The location of the water temperature and water pressure sensors is given in Fig. 6. In addition, three microphones (sensitivity $=4 \mathrm{mV} / \mathrm{Pa}$ ) were installed in the tunnel area for sound data acquisition as shown in Fig. 4 [14].

A remotely controlled PC for the data acquisition was placed in the TA7 access tunnel to TT66 (Fig. 4). A TPG 300 controller was also installed in the electronics bunker outside the high radiation area. Moreover, beam loss monitors (BLMs), beam position monitors, and beam current monitors were provided at the test facility in order to monitor the beam orbit and to obtain values for beam intensity and beam losses.

\section{OVERVIEW AND GOAL OF TESTS}

The goal of the tests was to verify the robustness and performance integrity of a fully assembled TCT following direct beam impact, reproducing unlikely but realistic fast failure scenarios in the LHC. Such scenarios included an asynchronous beam dump at nominal $7 \mathrm{TeV}$ conditions and important accident scenarios at $5 \mathrm{TeV}$ that have been considered during the LHC run 1 [7]. Three high-intensity impacts were foreseen to test different equivalent damage levels for the considered cases.

Since the collimator robustness tests were run using $440 \mathrm{GeV}$ proton beams, the beam intensity at $440 \mathrm{GeV}$, necessary to obtain the equivalent damage levels of the 5 and $7 \mathrm{TeV}$ accident scenarios to be studied, needed to be calculated respectively. Preliminary simulations were first performed with FLUKA to determine the equivalent intensity based on the equivalence of the energy peak for each case. Since different energy particles are involved (440 GeV compared to $5 \mathrm{TeV} / 7 \mathrm{TeV}$ ), the damage zone in the target might be different in the two cases, even if the peak values of the energy deposition for the SPS case and 
TABLE II. Main characteristics of the digital acquisition system and other equipment used in the experiment. The number of standard LHC collimator equipment is represented by $*$. The rest is equipment added specifically for the tests.

\begin{tabular}{lcccc}
\hline \hline Sensor type/equipment & Specification & Quantity & Acquisition range/bandwidth & Sampling frequency \\
\hline Position sensor (LVDT) & HCA 2000 & $7^{*}$ & $\ldots$ & $1 \mathrm{~Hz}$ \\
Jaw temperature sensor & PT100 & $4^{*}$ & $-200 \div 650^{\circ} \mathrm{C}$ & $1 \mathrm{~Hz}$ \\
Collimator tank temperature sensor & PT100 model S100820 & 2 & $-50 \div 260^{\circ} \mathrm{C}$ & $1 \mathrm{~Hz}$ \\
Water temperature sensor & PT100 & $1^{*}+1$ & $-100 \div 200{ }^{\circ} \mathrm{C}$ & $1 \mathrm{~Hz}$ \\
Water pressure sensor & CTE 9000 (signal 4-20 mA) & 2 & $100 \mathrm{mbar} \div 35 \mathrm{bar}$ & $1 \mathrm{~Hz}$ \\
Vacuum pressure sensor & Pirani gauge & 2 & $\sim 10^{-4} \div 1000 \mathrm{mbar}$ & $0.5 \mathrm{~Hz}$ \\
Microphone & B\&K 4939 & 3 & $4-100000 \mathrm{~Hz}$ & $\ldots$ \\
Stepper motor & Maccon SM 87.2.18M2N & $4^{*}+1$ & $5 \mu \mathrm{m}^{-}$ & $\cdots$ \\
End-position switch & Saia Burgess V3FN & $12^{*}$ & $\cdots$ & \\
\hline
\end{tabular}

for the LHC case are made equal by adjusting the intensity. Thus, using the intensity determined by FLUKA, detailed AUTODYN $^{\circledR}$ simulations [15] were then carried out to investigate if this intensity at $440 \mathrm{GeV}$ gave the same level

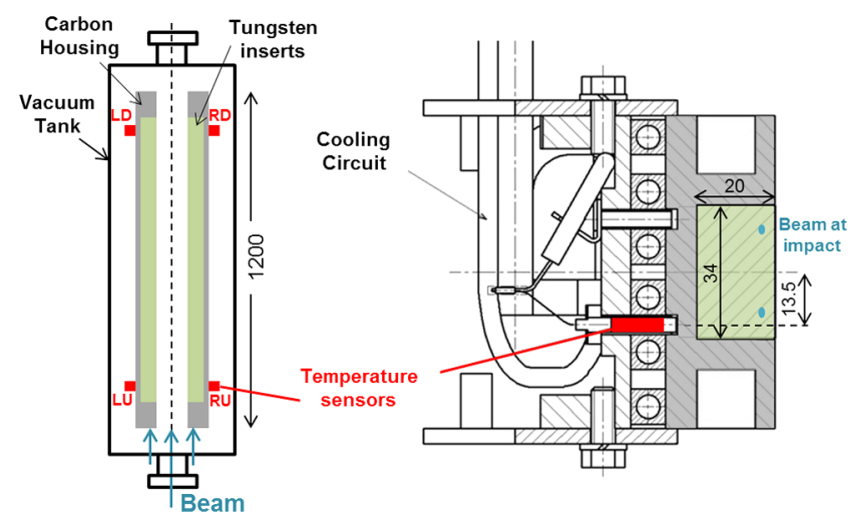

FIG. 5. Schematic diagrams of a standard horizontal tertiary collimator. Top view (left picture) and front view (right picture) of the cross-section of the left jaw assembly. The position of the jaw temperature sensors (left upstream (LU), left downstream (LD), right upstream (RU) and right downstream (RD)) is indicated. All dimensions are in $\mathrm{mm}$.

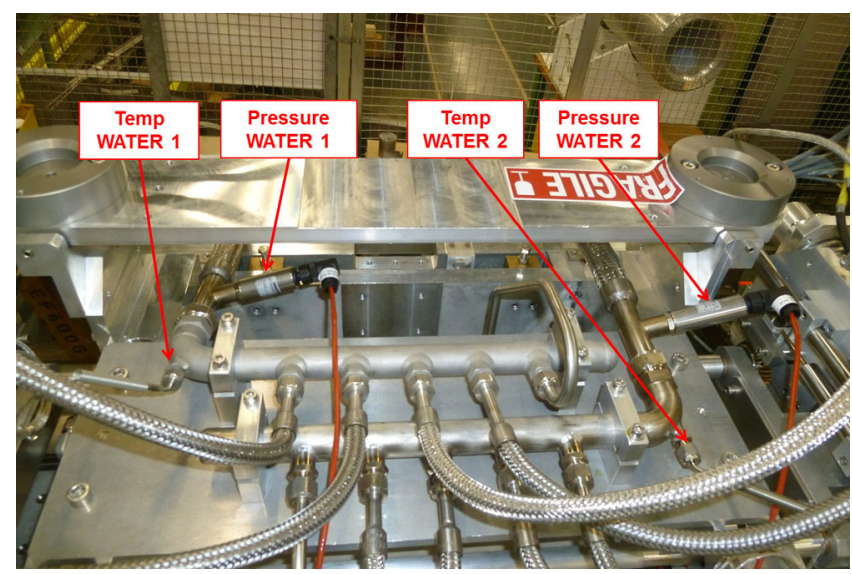

FIG. 6. Top view of the collimator prototype, indicating the location of water temperature and water pressure sensors. of damage produced on the jaw as obtained from the simulations of the $5 \mathrm{TeV} / 7 \mathrm{TeV}$ scenarios. If this was not the case, various other simulations were carried out, each time varying the intensity at $440 \mathrm{GeV}$, until an equivalent damage level was obtained between the $440 \mathrm{GeV}$ and $5 \mathrm{TeV} / 7 \mathrm{TeV}$ cases. This meant that a realistic equivalent intensity to be used in the tests was established, thus reproducing the studied cases more correctly. Table III compares the intensity and peak energy deposition for the LHC and SPS cases.

The equivalent damage was compared based on two direct effects of the beam impact: the damage extension on the tungsten jaw in terms of the dimensions (i.e. the height or radius) of the groove, and the maximum plastic deformation of the cooling pipes. Due to a large number of required SPS bunches, an equivalent damage level provoked on the cooling pipes was not reproducible in the HiRadMat facility for all the tests. It was thus concluded to use the equivalent intensity based on the damage extension of the tungsten surface for the three high intensity shots. It is important to point out that since the penetration depth of 5 and $7 \mathrm{TeV}$ protons is much longer than that of $440 \mathrm{GeV}$ protons, the damage equivalence in the target is in fact done in terms of the height of the groove only, and not of the length of the groove.

TABLE III. Comparison of the intensity and the peak energy deposition values for the LHC cases and the equivalent SPS cases to be studied. The equivalent intensity ( $I_{\text {equiv }}$ ) from FLUKA is based on the equivalent energy peak while $I_{\text {equiv }}$ from AUTODYN $^{\circledR}$ is based on the equivalent damage level. The peak energy deposition for the SPS cases is calculated based on $I_{\text {equiv }}$ from AUTODYN ${ }^{\circledR}$.

\begin{tabular}{|c|c|c|}
\hline Test & Test 1 & Test 3 \\
\hline Intensity, I-LHC cases $[\mathrm{p}]$ & $1.5 \times 10^{11}$ & $5.2 \times 10^{11}$ \\
\hline Peak energy deposition- & $2.237 \times 10^{6}$ & $5.531 \times 10^{6}$ \\
\hline LHC cases $[\mathrm{J} / \mathrm{kg}]$ & at $7 \mathrm{TeV}$ & at $5 \mathrm{TeV}$ \\
\hline$I_{\text {equiv }}$ at $440 \mathrm{GeV}[\mathrm{p}]-$ FLUKA & $3 \times 10^{12}$ & $7.5 \times 10^{12}$ \\
\hline$I_{\text {equiv }}$ at $440 \mathrm{GeV}[\mathrm{p}]-\mathrm{AUTODYN}^{\circledR}$ & $3 \times 10^{12}$ & $9.75 \times 10^{12}$ \\
\hline Peak energy deposition- & $2.143 \times 10^{6}$ & $6.964 \times 10^{6}$ \\
\hline SPS cases $[\mathrm{J} / \mathrm{kg}]$ & at $440 \mathrm{GeV}$ & at $440 \mathrm{GeV}$ \\
\hline
\end{tabular}



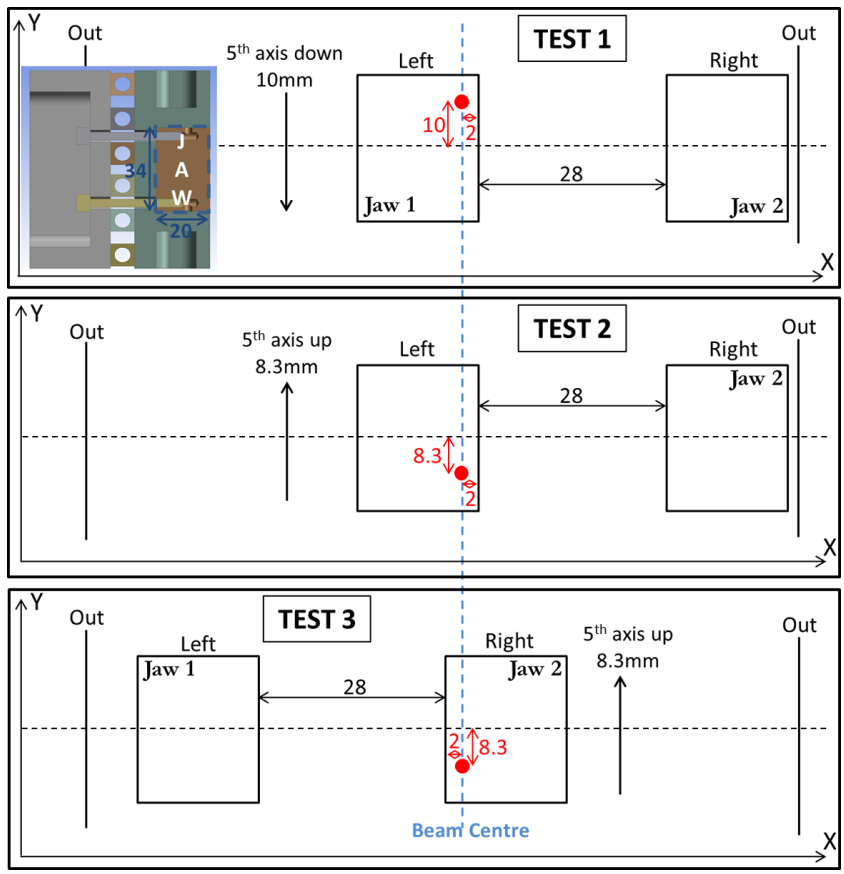

FIG. 7. Schematic diagrams for Tests 1-3. The schematic diagram of the jaw represents the area enclosed within the dotted blue line as shown here and in Fig. 3. The impact location is shown in red and all dimensions are in $\mathrm{mm}$.

The tests performed on the TCT are explained here. Details of the tests are given in Fig. 7. The objective of Test 1 ( $7 \mathrm{TeV}$-equivalent intensity of $3 \times 10^{12} \mathrm{p}$ ) was to investigate the effect of an asynchronous beam dump, inducing impact of one nominal LHC bunch on the TCT jaw. On the other hand, Test 2 ( $7 \mathrm{TeV}$-equivalent intensity of $\left.9 \times 10^{11} \mathrm{p}\right)$ was aimed to inspect the onset of damage caused by beam impact on the TCT. Finally, Test 3 (5 TeVequivalent intensity of $9.75 \times 10^{12} \mathrm{p}$ ) was designed to reproduce a disruptive scenario for asynchronous beam dump, involving the direct impact of 4 LHC bunches at $5 \mathrm{TeV}$, and to benchmark simulation results presented in [7] against these experimental results.

As indicated in Fig. 7, all tests were performed at an impact parameter of $2 \mathrm{~mm}$ from the outer surface. Such an impact parameter was chosen as a compromise in order to ensure that the bulk material of the jaw insert was hit during the experiment while still being a reasonable value for an asynchronous beam dump scenario. Hitting jaws at different locations was possible thanks to the fifth axis vertical movement $( \pm 10 \mathrm{~mm})$. The choice of the locations for the tests was done in such a way as to minimize interference between the high intensity shots in case of material projection. A beam size of $0.5 \mathrm{~mm}\left(\sigma_{x}\right) \times 0.5 \mathrm{~mm}\left(\sigma_{y}\right)$ was specified on the basis of HiRadMat output [13] for all the cases, although later it was shown by simulations that small changes in beam size do not considerably affect the damage extension in case of highly disruptive tests at the chosen impact parameter.

\section{BEAM TEST RESULTS}

\section{A. Beam-based alignment}

In order to ensure a precise location of the beam impact, a beam-based alignment (BBA) was required before each high-intensity shot. This was done with very safe intensity (using pilot bunch) to avoid damage that could compromise results. Prior to each high-intensity test, several lowintensity (on the order of $10^{9} \mathrm{p}$ ) beam extractions were used to correctly set up the beam line and the experiment (Fig. 8). This was essential in order to ensure an accurate setup for the tests with the correct impact parameter.

The same setup was performed on every day when measurement campaigns were performed. In order to ensure reproducibility of orbit and beam sigma, the same SPS cycle that is normally used in high-intensity operation was used for these tests. The procedure adopted was then to scrape down these high-intensity beams in the SPS to pilot intensity.

The left and the right jaws were respectively moved in steps (step sizes ranging from 0.25 to $1 \mathrm{~mm}$ ) and the developed losses, as measured from BLMs in the line, were recorded for each calibration shot. Alignment fits were generated for both jaws from which the beam center was determined (Fig. 9).

Table IV summarizes the sequence of the beam-based alignments and the tests, and gives the total intensity that the TCT has been subjected to during the tests. It can be

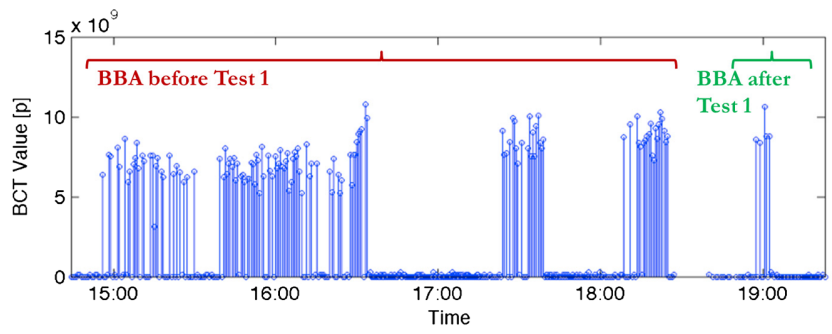

FIG. 8. Low-intensity SPS pilot beam extraction intensities used for the beam-based alignment (BBA) before and after Test 1 .

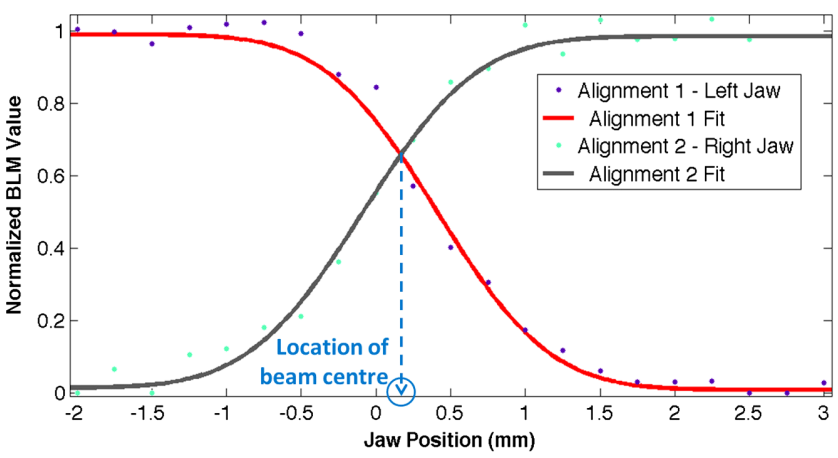

FIG. 9. One example of the alignment fits generated for the beam-based setup, showing movements with the left and right jaws in order to determine the location of the beam center. 
TABLE IV. Sequence of the tests. Tests 2 and 3 were carried out on a different day than Test 1 . The intensity of pilot and highintensity bunches is on the order of $10^{9}$ and $10^{11}$ protons, respectively.

\begin{tabular}{lcc}
\hline \hline Test & $\begin{array}{c}\text { Intensity } \\
{\left[\times 10^{11} \mathrm{p}\right]}\end{array}$ & $\begin{array}{c}\text { Number of } \\
\text { bunches }\end{array}$ \\
\hline BBA before Test 1 & 5.674 & 79 pilot \\
Test 1 & 33.6 & 24 high intensity \\
BBA after Test 1 & 1.5065 & 18 pilot \\
BBA before Test 2 & 4.049 & 35 pilot \\
Test 2 & 10.36 & 6 high intensity \\
BBA after Test 2/before & 2.32 & 22 pilot \\
Test 3 & & \\
Test 3 & 93.4 & 72 high intensity \\
Total & 147.9 & \\
\hline \hline
\end{tabular}

seen that following the beam-based alignments, each respective test could be performed using a high-intensity shot (on the order of $10^{12} \mathrm{p}$ ).

\section{B. Highlights of experimental measurements}

\section{Beam parameters of high-intensity tests}

The beam parameters used for each test, as well as their physical effect on the impacted jaw, are summarized in Table V. The precision on the beam size at impact is not better than $\sim 10 \%$.

\section{Surface integrity}

A beam-based setup was performed after Test 1 and Test 2 as an attempt to check the surface integrity of the jaws and the collimator mechanics following the beam shots. Major damage of the jaw might result in different values in the results of the BBA procedure. As can be observed from Fig. 10, there are no large variations between the beam positions before and after the shot, apparently indicating the absence of critical damage to the jaw surface. It is however difficult to conclude on errors in the range of $100 \mu \mathrm{m}$.

TABLE V. Summary of the test parameters.

\begin{tabular}{lccc}
\hline \hline Test & 1 & 2 & 3 \\
\hline SPS extraction intensity & 3.36 & 1.04 & 9.34 \\
$\quad\left[\times 10^{12}\right.$ p] & & & \\
Number of bunches & 24 & 6 & 72 \\
Average bunch intensity & 1.40 & 1.73 & 1.30 \\
$\quad\left[\times 10^{11}\right.$ p] & & & \\
Bunch spacing $[\mathrm{ns}]$ & 50 & 50 & 50 \\
Beam energy $[\mathrm{GeV}]$ & 440 & 440 & 440 \\
Beam size at impact & $0.375 \times$ & $0.5 \times$ & $0.49 \times$ \\
$\quad\left(\sigma_{x} \times \sigma_{y}\right)\left[\mathrm{mm}^{2}\right]$ & 0.375 & 0.5 & 0.49 \\
Energy on jaw $[\mathrm{kJ}]$ & 87.89 & 27.72 & 249.87 \\
TNT equivalent $[\mathrm{g}]$ & 21.01 & 6.62 & 59.72 \\
\hline \hline
\end{tabular}

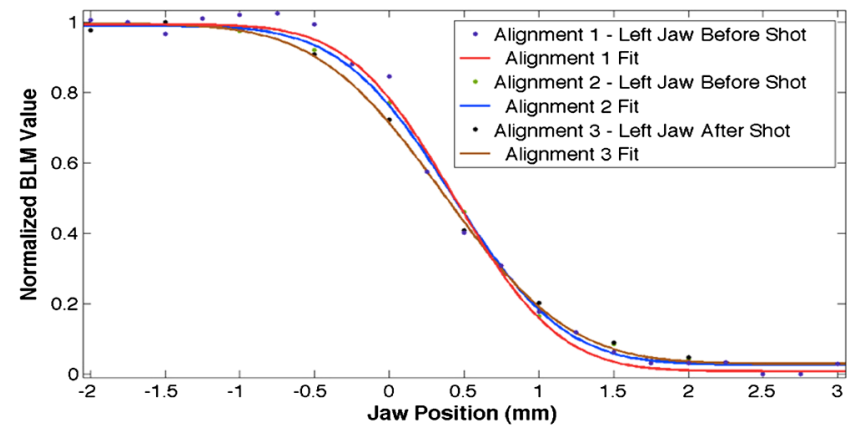

FIG. 10. Beam-based alignment of the left jaw. Alignment 1 and Alignment 2 are performed before Test 1, while Alignment 3 represents the check after Test 1 .

As will be shown in the preliminary post-mortem analysis (Sec. IV C), it results that grooves from Test 1 and Test 3 can be observed on the surface of the jaws. The reason why the alignment checks in Fig. 10 did not indicate the presence of such grooves might be because the grooves do not cover the full length of the jaw, and the unperturbed part at the end of the jaw still determines the closest point to the beam that in turn determines the alignment.

\section{Temperature and pressure measurements}

Temperature and pressure measurements were made during the three tests using the installed instrumentation. The temperature increases recorded are lower than expected and are not really compatible with the post-mortem observations presented later in this paper. This puts in question the validity of these measurements and, thus, these results have to be interpreted with care. In particular, the jaw temperature profiles show a temperature rise following the impact, which although clearly observable, is small. In fact, one of the reasons for these discrepancies might be the high thermal resistance (due to the low contact pressure) between the temperature probe and the support to which it is attached, leading to an incorrect temperature recording (refer to Sec. V B and Fig. 19). A peak in vacuum pressure for Test 1 is observed at the moment of impact. It is also noted that the vacuum pressure sensor only gave realistic results for Test 1 .

\section{Sound measurements}

Rapid energy deposition from proton beam on collimator jaws causes pressure waves inside the jaw material. Microphones capture the response of the whole collimator structure to this impulsive excitation, convolved by the acoustic transfer function of the reflective tunnel area specific to each microphone location [14]. The signals in Fig. 11 show the sound pressure during the beam impacts of the three test cases.

The rms value of the sound pressure level $\left(L_{p}\right)$ was calculated with a time constant of $125 \mathrm{~ms}$. A correlation was found between the total deposited energy and the 

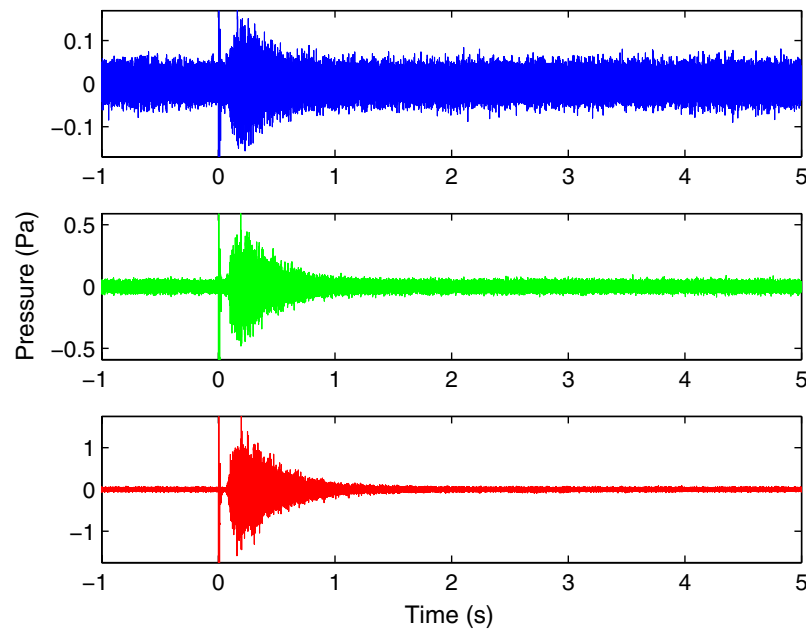

FIG. 11. Filtered signals during Test 2 (top), Test 1 (middle), and Test 3 (bottom) for microphone 1. A noise spike with a slow refraction decay is generated in the sensor electronics by radiation effects and it can be used as an event trigger of the beam impact. A high-pass filter of third order at $100 \mathrm{~Hz}$ removes the slow decay and reveals the real sound data.

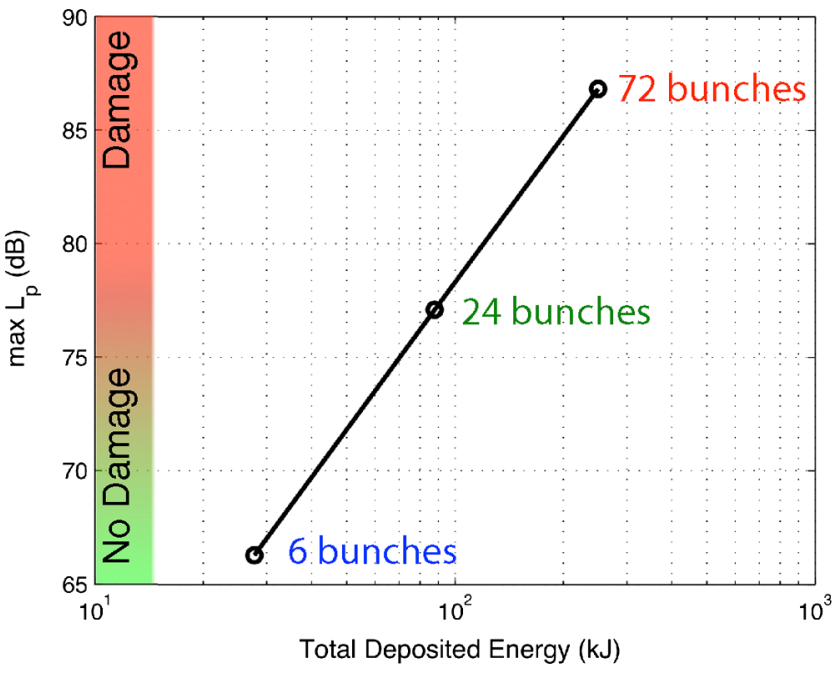

FIG. 12. Sound pressure level for microphone 1 vs the total deposited energy for test cases listed in Table V. Linear interpolation yields a reference curve which can be used to estimate the damage extent from the sound pressure level for the given setup and beam parameters.

maximum of the sound pressure level during the impact (Fig. 12).

\section{Preliminary post-mortem analysis}

Following the collimator robustness tests, measurements of the residual contact dose rates of the collimator were recorded at different locations. Two months after the experimental tests were performed, the hottest activation point of the collimator was found to be $\sim 100 \mu \mathrm{Sv} / \mathrm{h}$
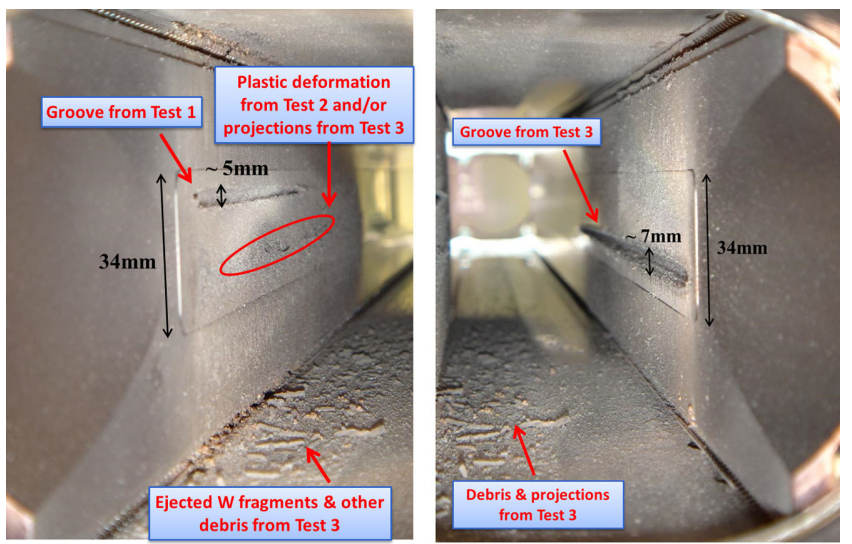

FIG. 13. Preliminary visual inspection. Damage on the left jaw caused mainly by Test 1 beam impact (left). Damage on the right jaw caused by Test 3 beam impact (right). Marked dimensions of the grooves only take into account the estimated height of the groove.

located around the middle of the collimator tank. The dose rate levels at the entrance window were much lower at a value of $\sim 20 \mu \mathrm{Sv} / \mathrm{h}$. After the necessary cooldown of the irradiated collimator, a preliminary visual inspection (Fig. 13) was then possible by means of a camera, in order to give a qualitative damage evaluation before further analysis can be carried out.

Grooves from Test 1 and Test 3 can clearly be identified, showing that there was a local temperature rise exceeding the melting point $\left(\sim 1343^{\circ} \mathrm{C}\right)$ of the $\mathrm{Cu}-\mathrm{Ni}$ phase of the jaw insert material. Moreover, various fragments and projections of tungsten can be also observed between the jaws, indicating that there was no melting of the tungsten itself. Vaporization deposit around the molten region is visible, implying the extent of the damage caused by the beam impacts and the risk for contamination and vacuum degradation. These preliminary observations served important to draw some crucial conclusions on safe $7 \mathrm{TeV}$ limits for TCTs and have helped to update collimator robustness limits [16].

\section{NUMERICAL BENCHMARKING}

\section{A. Simulation tools}

The fast and complex thermomechanical phenomena induced by the interaction of beam particles with matter, as well as the complexity of the collimator structure, make the implementation of a numerical approach through finite element analysis, as opposed to analytical solutions, highly necessary $[12,17]$. Nonlinear, transient analyses were thus performed to correctly evaluate the temperature distribution and other thermally induced effects due to beam impact. Such analyses were conducted using both ANSYS $^{\circledR}$ finite element code [18] (further detail in Sec. VB) and AUTODYN $^{\circledR}$ [19] (further detail in Sec. V C). 

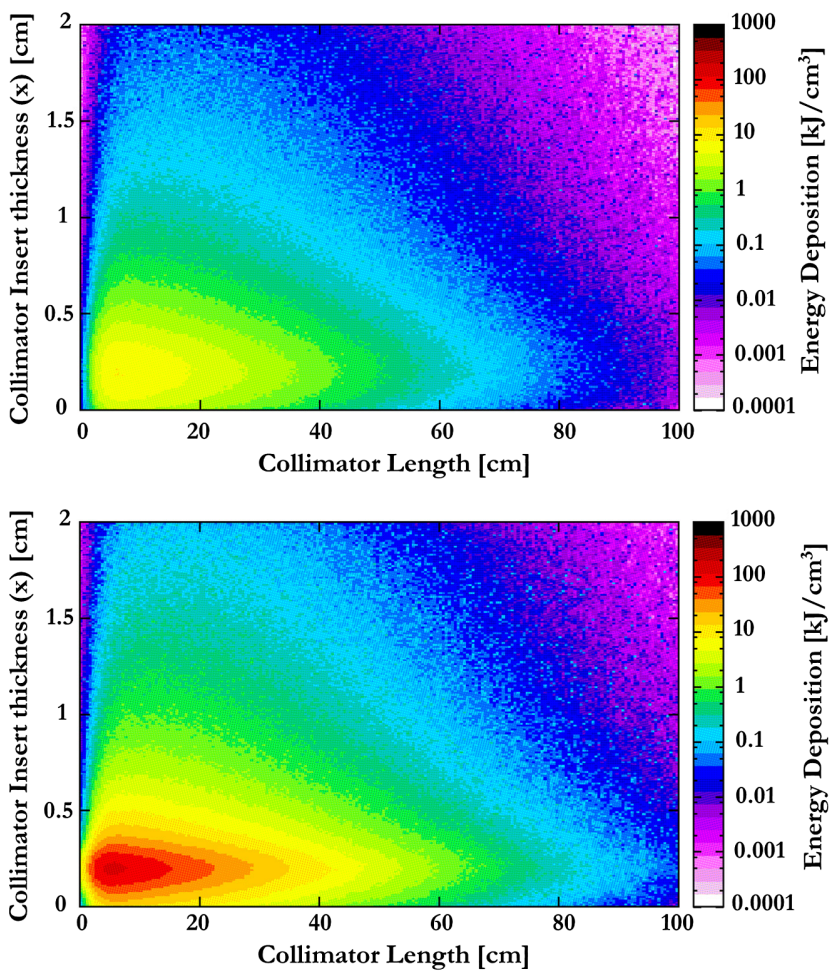

FIG. 14. Energy deposition $\left(\mathrm{kJ} / \mathrm{cm}^{3}\right)$ cuts at the maximum temperature on the tungsten inserts in longitudinal section, as calculated by FLUKA for Test 1 (top) and Test 3 (bottom) at the end of the impact.

FLUKA [20,21] models were set up and full shower simulations provided energy deposition distributions for the studied accident cases which have been defined by accelerator physics studies (Fig. 14). These 3D maps were then loaded in the ANSYS ${ }^{\circledR}$ and AUTODYN ${ }^{\circledR} 3 \mathrm{D}$ models through dedicated subroutines in order to provide the input thermal load in terms of power density distribution. A beam size of $0.53 \mathrm{~mm}\left(\sigma_{x}\right) \times 0.36 \mathrm{~mm}\left(\sigma_{y}\right)$ was used for simulating the three test cases. Moreover, a mesh size of $0.1 \mathrm{~mm}(x) \times 0.1 \mathrm{~mm}(y) \times 5 \mathrm{~mm}(z)$, at the location of the maximum energy deposition, was found to be the minimum required so that a further mesh size reduction does not significantly increase the estimated peak power density.

The high pressure produced in the deposition region after impact generates a radially outgoing shock wave, followed by a rarefaction wave that leads to a density reduction between one bunch and the next. In practice, the protons in subsequent bunches will penetrate much deeper into the target and thus, once the error in density becomes too high, FLUKA should be run iteratively with the modified density distribution obtained from ANSYS $^{\circledR} /$ AUTODYN $^{\circledR}$ in order to provide an updated energy deposition map [22]. According to previous work [23], a suitable iteration step is considered to be the time interval during which the target density decreases by $15 \%-20 \%$.

In the cases studied in this paper, the temperature and density variations for Test 3 (most loaded test case) have

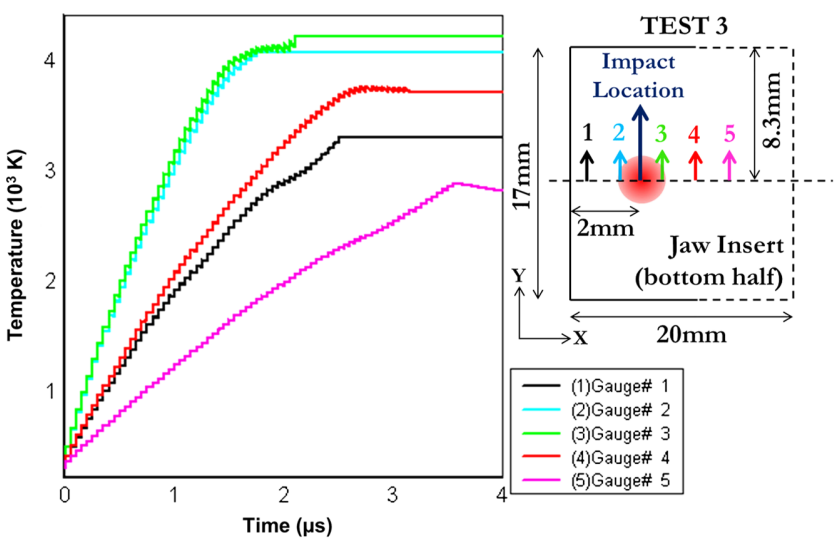

FIG. 15. Temperature profiles over time for Test 3 at five different gauges placed at the most loaded longitudinal section. The gauges are located at the vertical position of the impact, as indicated on the cross-sectional schematic diagram of the bottom half of the jaw insert. Gauge 1 is at $0.5 \mathrm{~mm}$ from the external surface, Gauge 2 is $1 \mathrm{~mm}$ distant from Gauge 1, Gauge 3 is $1 \mathrm{~mm}$ from Gauge 2, and so on for Gauge 4 and Gauge 5.

been monitored with five gauges placed at the most loaded longitudinal collimator section. Figure 15 gives the temperature plot during the energy deposition at the five locations indicated on the schematic diagram. Moreover, the density plot in Fig. 16 shows that the most loaded element, which from the temperature plot in Fig. 15 is represented by Gauge 3 , has a $12 \%$ density reduction which is within the acceptable target density reduction range quoted in [23].

Thus, since for these studied cases, the change of density induced by the impinging particles is within the acceptable density reduction range, it is justified to assume that the density remains constant for the duration of the impact. Therefore, an uncoupled FLUKA-ANSYS ${ }^{\circledR} /$ AUTODYN $^{\circledR}$ approach was used, meaning that the energy deposition calculated for the first bunch on the pristine material was

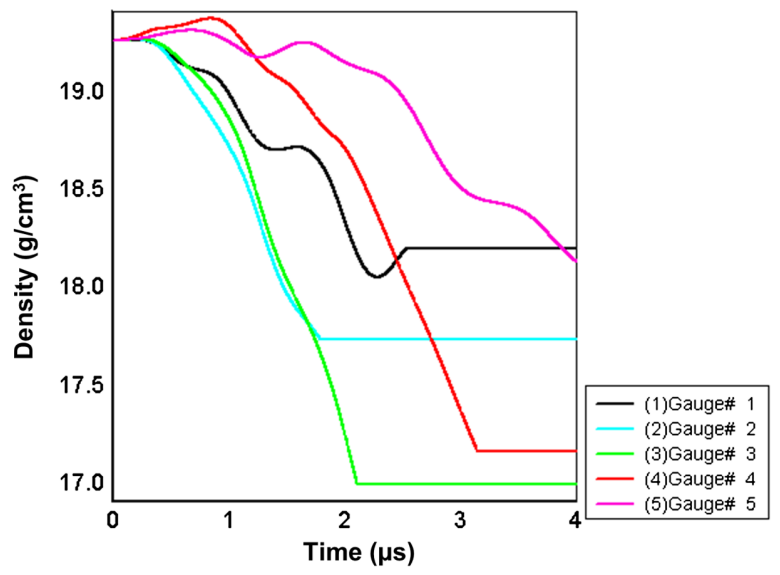

FIG. 16. Density profiles over time for Test 3 at five different gauges placed at the most loaded longitudinal section. The gauge locations are the same as indicated on the schematic diagram in Fig. 15. 
TABLE VI. Summary of the test parameters as simulated by ANSYS $^{\circledR}$.

\begin{tabular}{lccc}
\hline \hline Test & 1 & 2 & 3 \\
\hline SPS extraction intensity & 3.36 & 1.04 & 9.34 \\
$\quad\left[\times 10^{12} \mathrm{p}\right]$ & & & \\
$\quad$ Number of bunches & 1 & 1 & 1 \\
Simulated bunch intensity & 3.36 & 1.04 & 9.34 \\
$\quad\left[\times 10^{12} \mathrm{p}\right]$ & & & \\
Thermal shock duration, & 1.174 & 0.256 & 3.622 \\
$\quad \tau_{\text {shock }}[\mu$ s $]$ & & & \\
Beam size at impact & $0.53 \times$ & $0.53 \times$ & $0.53 \times$ \\
$\quad\left(\sigma_{x} \times \sigma_{y}\right)\left[\mathrm{mm}^{2}\right]$ & 0.36 & 0.36 & 0.36 \\
Energy on jaw $[\mathrm{kJ}]$ & 87.89 & 27.72 & 249.87 \\
TNT equivalent $[\mathrm{g}]$ & 21.01 & 6.62 & 59.72 \\
\hline \hline
\end{tabular}

maintained also for subsequent bunches. The same approach was followed for similar calculations on other structures [24].

\section{B. Implicit code $\left(\right.$ ANSYS $\left.^{\circledR}\right)$ analysis}

A first preliminary assessment of the extent of beaminduced damage can be done by evaluating the maximum temperatures reached and consequently the extent of the molten region. These simulations were performed with the implicit code ANSYS ${ }^{\circledR}$. The same mesh size as in FLUKA was used at the location of the maximum energy deposition, with a coarser mesh applied to the other collimator components due to computational requirements. Table VI gives a summary of the simulated test parameters and Fig. 17 shows the different peak temperatures reached along the jaw for the three tests.

Heating processes due to particle beam impacts are extremely fast. The thermal shock typically lasts from few nanoseconds to some microseconds, depending on the bunch structure of the incoming beam. As shown by Kalbreier et al. [25], it is possible to assume that no heat diffusion occurs during the thermal shock because the characteristic thermal diffusion time, $\tau_{\text {diffusion, }}$ is much longer than the thermal shock duration, $\tau_{\text {shock }}$.

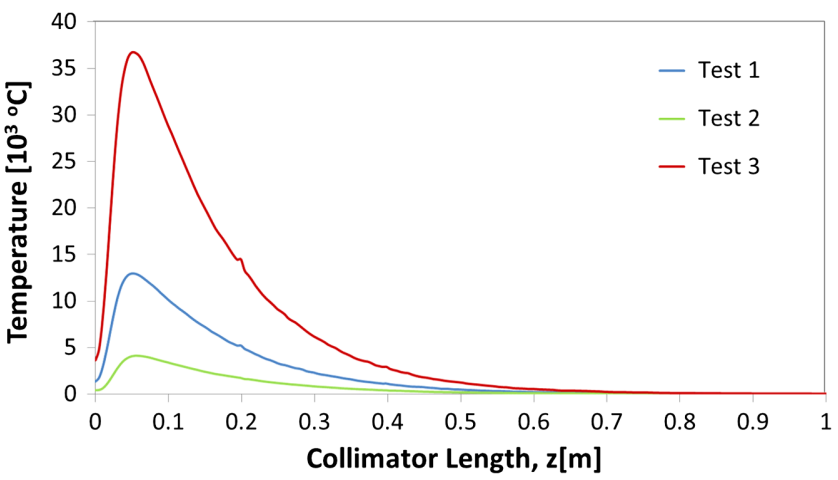

FIG. 17. Temperature peak profiles within the jaw inserts as a function of distance along the beam direction.
Equations (1) and (2) were used to calculate $\tau_{\text {diffusion }}$ for the jaw inserts (material: Inermet 180) and it was found to be $\sim 306 \mu$ s, considering the transverse edge length of one mesh element $(0.1 \mathrm{~mm})$ as the typical dimension of the structure. Table VI shows that the three test situations entail a rapid energy deposition on the range of a few microseconds (Test 1: $1.174 \mu \mathrm{s}$, Test 2: $0.256 \mu \mathrm{s}$, Test 3: $3.622 \mu \mathrm{s}$ ), considering a bunch length of $1 \mathrm{~ns}$ and a bunch spacing of $50 \mathrm{~ns}$. Thus, the thermal shock duration is much shorter than the thermal diffusion time, therefore concluding that the heat diffusion does not play a significant role and could be neglected during the deposition of the energy. This justifies the assumption to consider the deposited energy as linearly growing during the thermal shock (Fig. 18). Thus, the system could be simulated in a way that the local temperature increases linearly with energy deposition (in time) since limited heat diffusion on relatively small volumes prevents the temperature to decrease between one bunch and the following. Equations (1) and (2) are given by:

$$
\begin{gathered}
\tau_{\text {diffusion }}=\frac{l^{2}}{\kappa_{c c}}, \\
\kappa_{c c}=\frac{k}{\rho c_{p}},
\end{gathered}
$$

where $l$ is the typical dimension along which heat diffusion may occur, $\kappa_{c c}$ is the thermal diffusivity, $k$ is the thermal conductivity, $\rho$ is the density, and $c_{p}$ is the specific heat capacity at constant pressure.

Moreover, the system was considered as adiabatic during the thermal shock duration, meaning that no heat exchange through the outer surface of the collimator is taken into account, so the total deposited energy remains constant.

In order to benchmark simulations, the evolution of temperature as a function of time, at the location where the

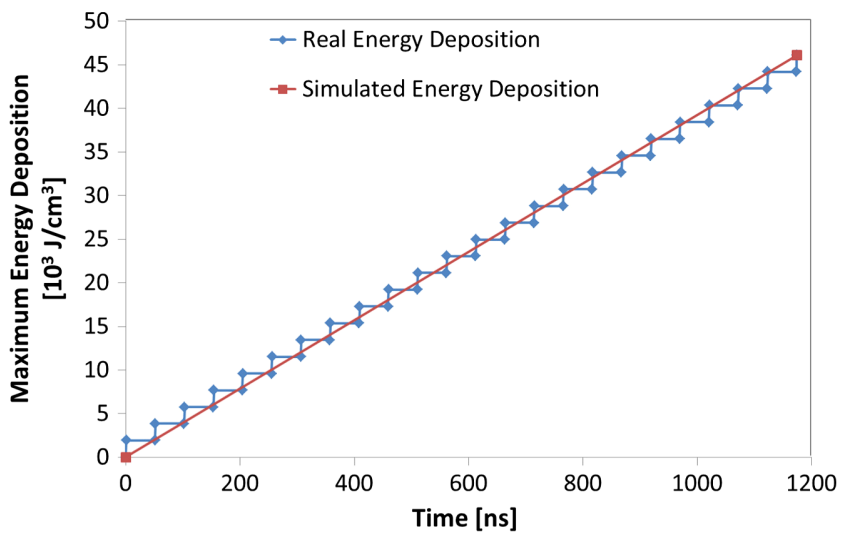

FIG. 18. Comparison of the real and simulated energy depositions for Test 1 (24 bunches). The real energy deposition is performed bunch by bunch while in the simulations, the local temperature is taken to increase linearly with energy deposition (in time) due to the limited heat diffusion assumption. 


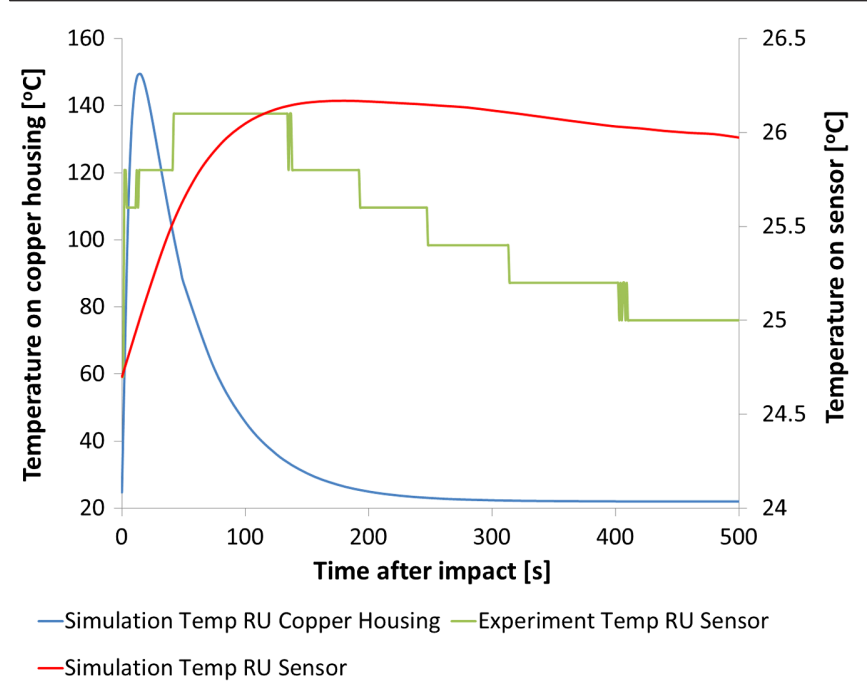

FIG. 19. Comparison of experimental and simulation thermal transients at probe location for Test 3. The left axis represents the temperature at probe location [right upstream (RU)] on the copper housing (blue curve) while the right axis represents the temperatures given by the sensor (RU) in the experiment (green curve) and in the simulations (red curve). It can be observed that modeling a low contact pressure between the sensor and the copper housing (red curve) gives temperature profiles that are more similar to the ones recorded during the experiment (green curve).

jaw temperature sensors have been installed on the collimator jaw for the experiment, were simulated for each test. Originally, the temperature of the copper housing at the location of the sensor was taken but this showed a much more significant temperature rise than that captured by the sensors in the experiment. The sensor was then modeled as a small component, placed with a certain thermal conductance value between it and the copper housing, at the location of the sensor. Such an approach led to more similar temperature profiles with respect to the experimental ones, with a thermal conductance value of $0.5 \mathrm{~W} / \mathrm{m}^{2} \mathrm{~K}$ giving the closest temperature profile, both in terms of maximum temperature reached as well as temperature profile over time. This means that during the experiment, the contact pressure between the temperature sensor and the copper housing was extremely low, leading to an incorrect temperature recording. The outcomes for Test 3 are shown in Fig. 19.

At this stage, the tested collimator cannot be extensively manipulated due to the high radiation level. Thus, based on preliminary observations (no detailed metrology), the only structural comparison between the experiment and simulations is, so far, limited to the dimension and shape of the groove generated by the beam impacts on the tungsten inserts. However, detailed simulations by AUTODYN ${ }^{\circledR}$ (refer to Sec. VC) show that in addition to the groove, there is a region around the groove where the material undergoes plastic deformation, meaning that in reality the damage extent is larger than the groove itself.

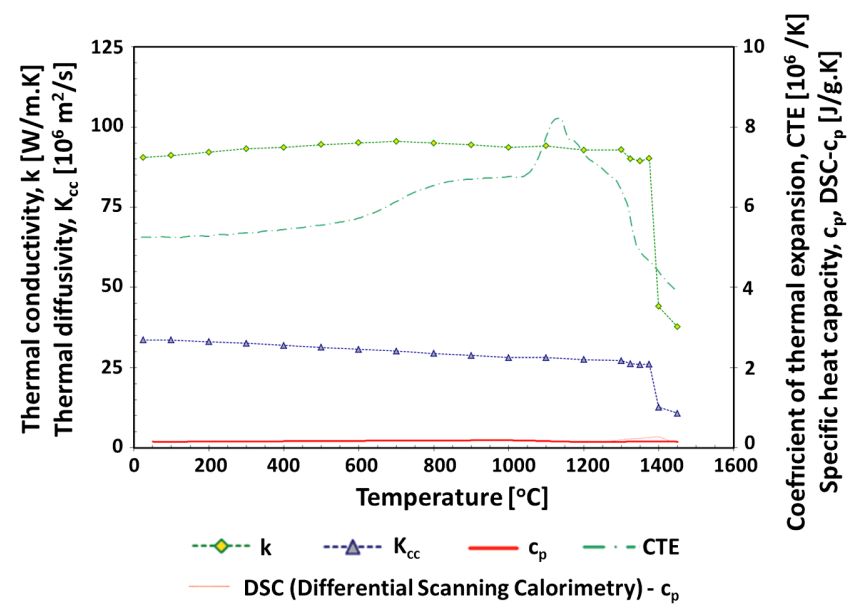

FIG. 20. Thermal properties of Inermet 180 measured up to $1450{ }^{\circ} \mathrm{C}[26]$.

In order to visualize the groove generated by each beam impact, the molten region was investigated in ANSYS $^{\circledR}$ using material properties for the jaw inserts as obtained from a full thermal characterization performed on Inermet 180 (Fig. 20) [26]. The melting point of the jaw inserts is considered as $1343^{\circ} \mathrm{C}$ which, as already explained in $\mathrm{Sec}$. IV $\mathrm{C}$, is the melting temperature of the $\mathrm{Cu}-\mathrm{Ni}$ phase of the jaw insert material.

Figures 21, 22, and 23 illustrate the target damage by showing the extent of the molten regions for the three tests together with a qualitative comparison of the shapes and dimensions of the real grooves. It is important to point out that the molten volume is not necessarily exactly identical to the removed volume (observed groove size) since some solid fragments are actually ejected by inner highly energetic volumes.

The graph in Fig. 24 then summarizes the groove sizes for the three tests that have been presented in this subsection and provides a comparison of the damage extent between the observed and simulated values.

\section{Explicit code (AUTODYN ${ }^{\circledR}$ ) analysis}

In the preceding subsection (Sec. V B), the method adopted to simulate the thermal field evolution on the collimator after beam impact has been described. When aiming to simulate more complex phenomena like shockwave generation, phase change and material ejection, one has to resort to advanced explicit wave propagation codes like AUTODYN ${ }^{\circledR}$. The accuracy of results obtained with these numerical tools depends on the reliability of the implemented material models, constituted by: (i) equation of state (EOS) - expresses the pressure as a function of two independent variables such as density and internal energy (or temperature); (ii) strength model-controls the deviatoric behavior of the material, usually keeping into account the contribution of strain, strain rate and temperature; (iii) failure model-contains the set of conditions of the 

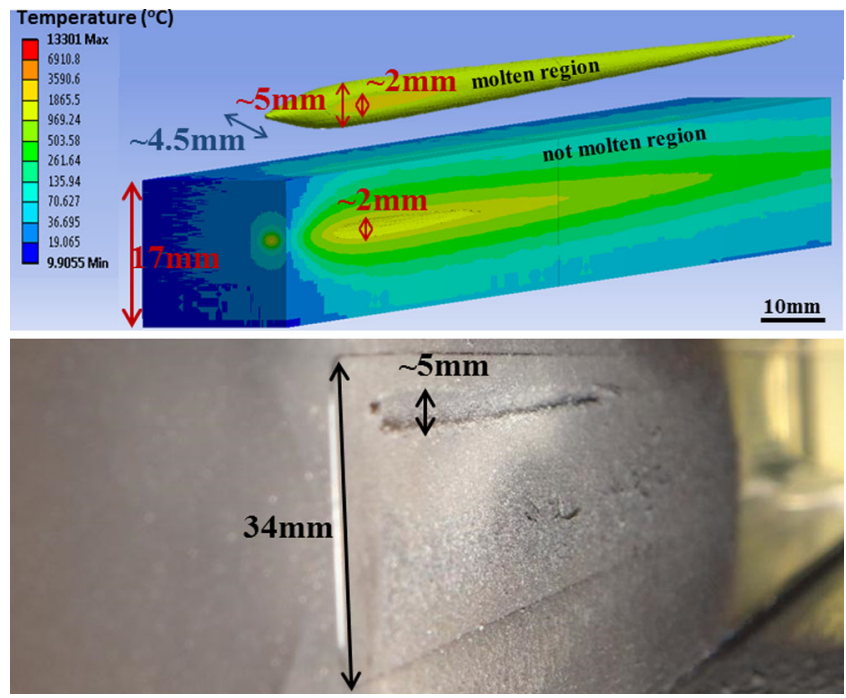

FIG. 21. The extent of the molten region caused by Test 1 beam impact, resulting in a groove on the top half of the first Inermet 180 jaw insert block, as simulated by ANSYS $^{\circledR}$ on the left jaw. At first glance, a groove with a height of only $2 \mathrm{~mm}$ is observed on the surface of the jaw insert. However, it results that the volume of molten material is even larger inside the insert with the dimension of the molten region being in fact $5 \mathrm{~mm}$. Moreover, the molten region inside the jaw insert extends also to the second insert block. Marked dimensions of the grooves only take into account the estimated height of the groove.

material bulk failure, and its choice heavily depends on the physical fracture mechanism.

The material model developed for Inermet 180 in [7] has been benchmarked with another complementary experiment in the HiRadMat facility on advanced collimator materials [11]. Material models [27] and beam characteristics adopted for the numerical simulations with AUTODYN $^{\circledR}$ are resumed in Table VII. The EOS used

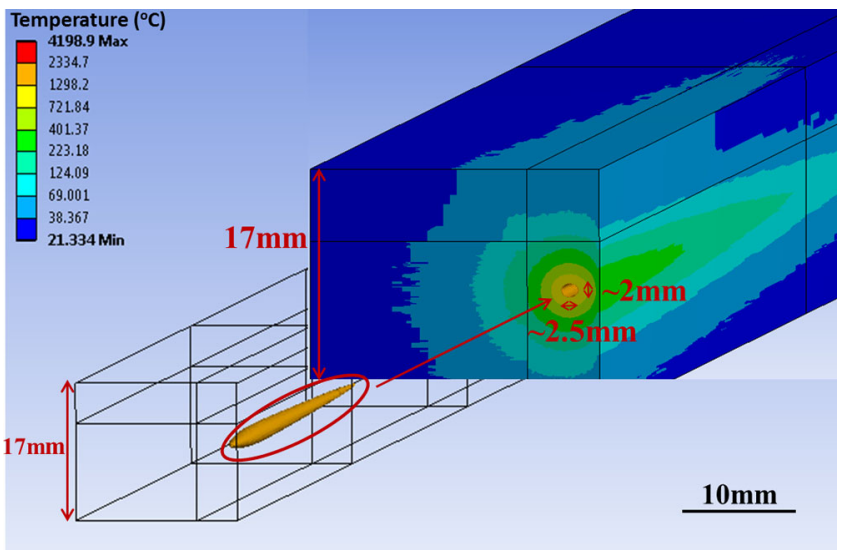

FIG. 22. No groove appears on the surface of the bottom half of the left jaw as shown for Test 2 in Fig. 13, however a small volume of molten material exists within the insert, which means that there may be some structural changes to the material inside the bottom half of the first jaw insert block.

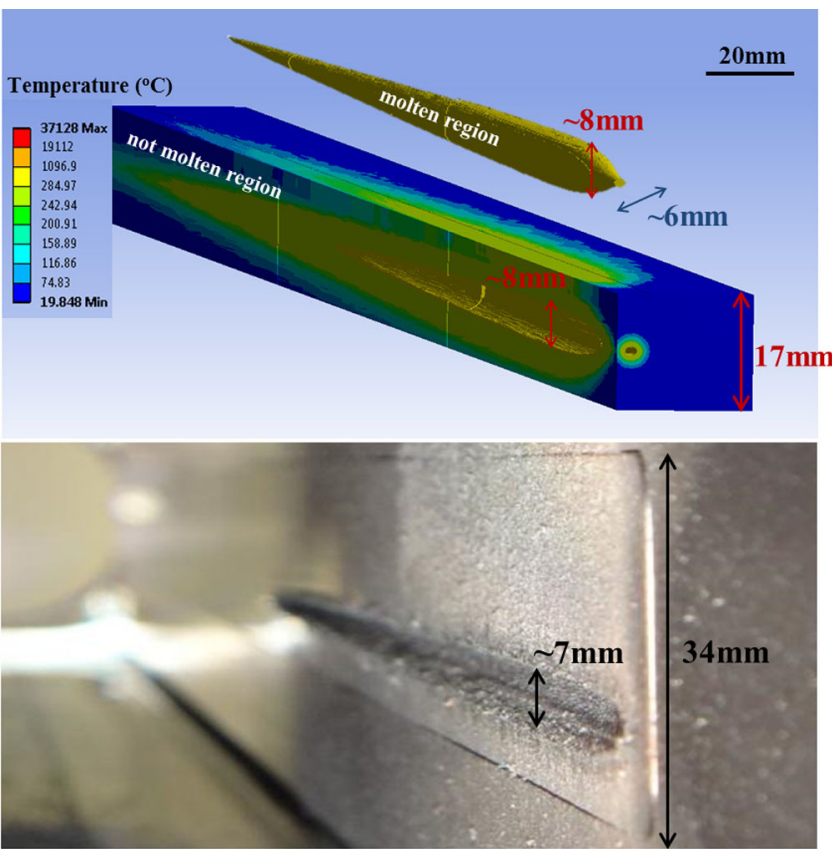

FIG. 23. The extent of the molten region caused by Test 3 beam impact, resulting in a groove on the bottom half of the first two Inermet 180 insert blocks, as simulated by ANSYS $^{\circledR}$ on the right jaw. It can be observed that the volume of molten material inside the insert extends partly to the third insert block. Marked dimensions of the grooves only take into account the estimated height of the groove.

in this work is the tabular SESAME N.3550 [28]. It has been devised for pure tungsten, for which experimental Hugoniot data are close to those of W-Ni-Cu heavy alloys [29] (Fig. 25).

In order to numerically visualize the groove generated by each beam impact, simulations have also been performed with the smoothed-particle hydrodynamics technique in AUTODYN $^{\circledR}$. In this computational method, the material is modeled by discrete elements (particles) with a spatial distance of interaction (smoothing length) over which their

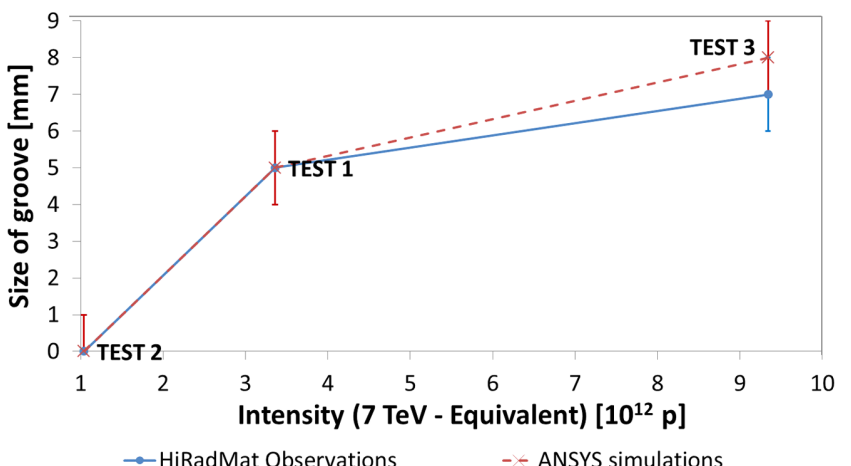

FIG. 24. Summary plot with a comparison of the damage extent between the observed and simulated values for the three tests. 
TABLE VII. Beam characteristics and jaw material models adopted for AUTODYN ${ }^{\circledR}$ simulations.

\begin{tabular}{|c|c|c|c|}
\hline & Test 1 & Test 2 & Test 3 \\
\hline Pulse intensity $\left[\times 10^{12} \mathrm{p}\right]$ & 3.36 & 1.04 & 9.34 \\
\hline Number of bunches & 24 & 6 & 72 \\
\hline $\begin{array}{l}\text { Simulated bunch intensity } \\
\qquad\left[\times 10^{11} \mathrm{p}\right]\end{array}$ & 1.40 & 1.73 & 1.30 \\
\hline Bunch spacing $[\mathrm{ns}]$ & 50 & 50 & 50 \\
\hline Beam size at impact & $0.53 \times$ & $0.53 \times$ & $0.53 \times$ \\
\hline$\left(\sigma_{x} \times \sigma_{y}\right)\left[\mathrm{mm}^{2}\right]$ & 0.36 & 0.36 & 0.36 \\
\hline EOS & \multicolumn{3}{|c|}{ SESAME table } \\
\hline Strength model & \multicolumn{3}{|c|}{ Johnson-Cook } \\
\hline Failure model & \multicolumn{3}{|c|}{ Hydro(Pmin) } \\
\hline
\end{tabular}

properties are weighed by a kernel function. For example, material density $\rho$ at a given position $x$ is given by:

$$
\rho_{x}=\sum_{j=1}^{n} m_{j} W\left(\left|x-x_{j}\right|, h\right),
$$

where $m_{j}$ is the mass of particle $j, W$ is the kernel function, and $h$ is the smoothing length.

Qualitative results of the grooves generated by the beam impacts, as obtained by AUTODYN ${ }^{\circledR}$, are also shown in Figs. 26, 27, and 28. In these cases, the numerical model only contains the first Inermet 180 jaw insert block.

Simulation outcomes for Test 1 and Test 3 show good accordance with visual inspections, while it is impossible to visualize the plastic damage produced by Test 2 . The zone is in fact covered with particles ejected from the opposite jaw during Test 3, which reached a velocity of about $1 \mathrm{~km} / \mathrm{s}$

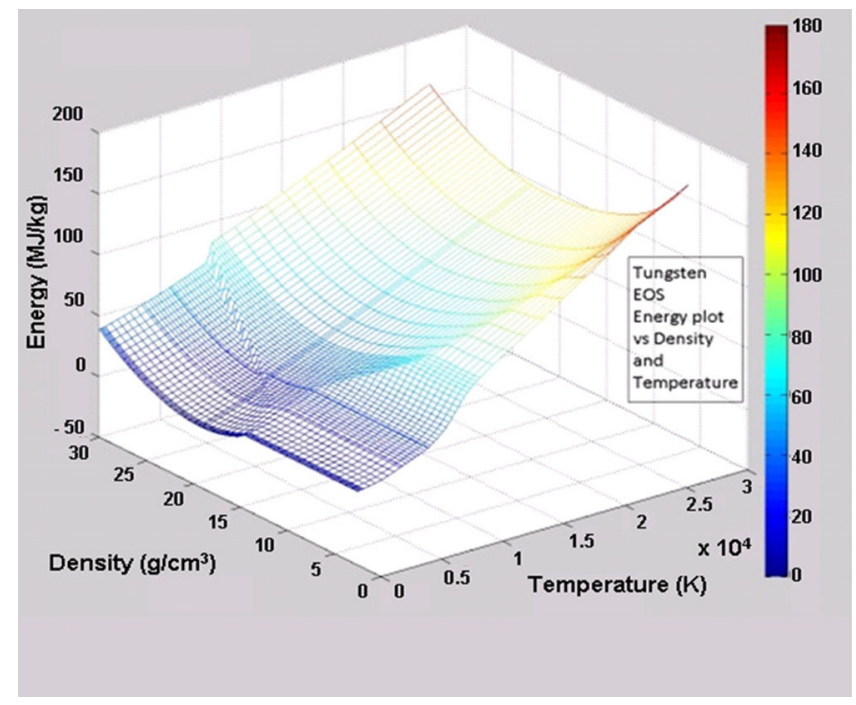

FIG. 25. A 3D plot of the SESAME (temperature vs density vs energy) used as the EOS for tungsten.

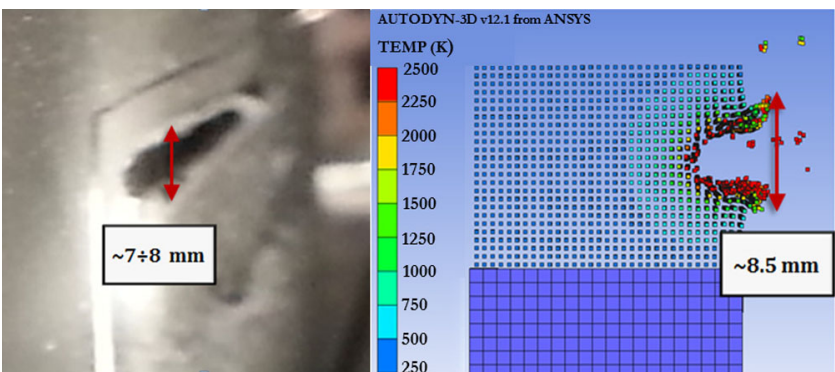

FIG. 26. Qualitative numerical benchmarking of the damage generated on the first Inermet 180 jaw block by Test 1 beam impact. Marked dimensions of the grooves extend to also take into account the plastically deformed zone in addition to the groove height.

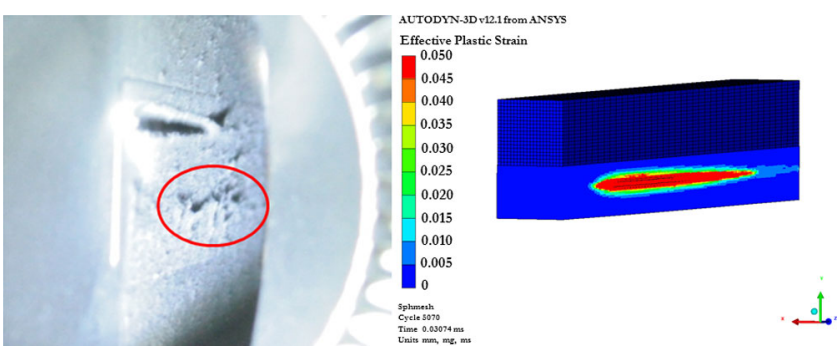

FIG. 27. Qualitative numerical benchmarking of the damage generated on first Inermet 180 jaw block by Test 2 beam impact. Note that the impacted zone is covered by particles from the opposite jaw produced during Test 3.

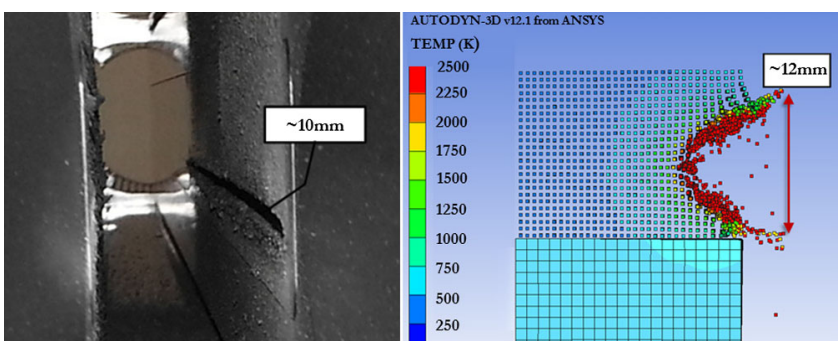

FIG. 28. Qualitative numerical benchmarking of the damage generated on the first Inermet 180 jaw block by Test 3 beam impact. Marked dimensions of the grooves extend to also take into account the plastically deformed zone in addition to the groove height.

according to simulations. The damage produced during Test 2 will be evaluated during future metallographic inspections once the equivalent dose of the collimator will be low enough.

\section{CONCLUSIONS}

Predicting the consequences of highly energetic particle beams impacting protection devices such as collimators is a 
fundamental issue in the design of state-of-the-art accelerator facilities for high energy particle physics. An experiment has recently been designed and carried out at the CERN HiRadMat facility in order to investigate the robustness and effects of beam accidents on a fully assembled collimator, based on accident scenarios in the LHC.

The performed tests entailed the controlled impact of intense and energetic proton pulses on both jaws of a tertiary collimator. Preliminary results and visual inspection of the outcome of these tests have been presented and discussed. The extent of the damage caused on the jaws of the collimator can already be observed and good agreement with the results of advanced simulations has been achieved. One immediate outcome from these tests is to define new safe $7 \mathrm{TeV}$ limits for TCTs. Damage thresholds in case of an asynchronous beam dump accident on a TCT have been identified, with the threshold for the onset of plastic damage set to $5 \times 10^{9} \mathrm{p}$, the limit for tungsten fragment ejection set to $2 \times 10^{10} \mathrm{p}$ and the limit for fifth axis compensation (with severe plastic deformation and fragment ejection) set to $1 \times 10^{11} \mathrm{p}$.

Moreover, an extensive postirradiation campaign, implying further direct observations, nondestructive and destructive testing, is foreseen in the near future in order to provide additional valuable information. Such investigations will provide a thorough, integral assessment of beam accident scenarios together with a more in-depth view of the robustness and effects of beam impacts on a TCT.

\section{ACKNOWLEDGMENTS}

This research has been supported by CERN, EuCARD, University of Malta, and EU FP7 HiLumi LHC (Grant Agreement No. 284404). Moreover, the authors would like to highly acknowledge the contribution of various teams to this experiment: HiRadMat team, FLUKA team, DGS-RP (C. Theis and K. Weiss), EN-STI (A. Masi, J. Lendaro, and R. Bebb), BE-ABP (R. Bruce and G. Valentino) and ENMME (N. Mariani). The work of H. Richter (CERN, DGS/ RP) and D. Campanini (CERN, EN/MME) in developing and making available FLUKA-ANSYS ${ }^{\circledR}$ and FLUKAAUTODYN $^{\circledR}$ interfaces is also acknowledged.

[1] O. Brüning, P. Collier, P. Lebrun, S. Myers, R. Ostojic, J. Poole, P. Proudlock, "The LHC Design Report," CERN Technical Report, CERN, Geneva, 2004 [http://ab-div.web .cern.ch/ab-div/Publications/LHC-designreport.html].

[2] R. Schmidt, R. Assmann, E. Carlier, B. Dehning, R. Denz, B. Goddard, E. Holzer, V. Kain, B. Puccio, B. Todd, J. Uythoven, J. Wenninge, and M. Zerlauth, New J. Phys. 8, 290 (2006).

[3] O. Brüning, P. Collier, P. Lebrun, S. Myers, R. Ostojic, J. Poole, and P. Proudlock, "The LHC Design Report, Chapter 18-Beam Cleaning and Collimation System," CERN Technical Report, CERN, Geneva, 2004 [http://
ab-div.web.cern.ch/ab-div/Publications/LHC-designreport .html].

[4] R. Assmann, O. Aberle, G. Bellodi, A. Bertarelli, C. Bracco, H. Braun, M. Brugger, S. Calatroni, R. Chamizo, A. Dallocchio et al., in Proceedings of the 10th European Particle Accelerator Conference, Edinburgh, Scotland, 2006 (EPS-AG, Edinburgh, Scotland, 2006), pp. 986-988.

[5] R. Assmann, I. Baishev, M. Brugger, L. Bruno, H. Burkhardt, G. Burtin, B. Dehning, C. Fischer, B. Goddard, E. Gschwendtner et al., in Proceedings of the 8th European Particle Accelerator Conference, Paris, France, 2002 (EPS-IGA and CERN, Geneva, 2002), pp. 197-199.

[6] R. Assmann, B. Goddard, E. B. Vossenberg, and E. Weisse, CERN Technical Report No. LHC-PROJECT-NOTE-293, CERN, Geneva, 2002.

[7] A. Bertarelli, V. Boccone, F. Carra, F. Cerutti, A. Dallocchio, N. Mariani, L. Peroni, and M. Scapin, Technical Report, EuCARD Conference Paper No. EuCARD-CON-2011068, CERN, Geneva, 2011.

[8] R. Bruce, R. Assmann, F. Burkart, M. Cauchi, D. Deboy, L. Lari, S. Redaelli, A. Rossi, B. Salvachua, G. Valentino, and D. Wollmann, in Proceedings of Chamonix 2012 Workshop on LHC Performance, Chamonix, France, 2012, pp. 183-188.

[9] L. Lari, R. Assmann, V. Boccone, R. Bruce, F. Cerutti, A. Rossi, V. Vlachoudis, A. Mereghetti, and A. Faus-Golfe, in Proceedings of 3rd International Particle Accelerator Conference, New Orleans, Louisiana, USA, 2012 (IEEE, Piscataway, NJ, 2012), Vol. C1205201, pp. 547-549.

[10] I. Efthymiopoulos, C. Hessler, H. Gaillard, D. Grenier, M. Meddahi, P. Trilhe, A. Pardons, C. Theis, N. Charitonidis, S. Evrard, H. Vincke, and M. Lazzaroni, in Proceedings of 2nd International Particle Accelerator Conference, San Sebastián, Spain (EPS-AG, Spain, 2011), Vol. C110904, pp. 1665-1667.

[11] A. Bertarelli, E. Berthome, V. Boccone, F. Carra, F. Cerutti, N. Charitonidis, C. Charrondiere, A. Dallocchio, P. Fernandez Carmona, P. Francon et al., Nucl. Instrum. Methods Phys. Res., Sect. B 308, 88 (2013).

[12] A. Bertarelli, O. Aberle, R. Assmann, E. Chiaveri, T. Kurtyka, M. Mayer, R. Perret, and P. Sievers, in Proceedings of the 9th European Particle Accelerator Conference, Lucerne, Switzerland, 2004 (EPS-AG, Lucerne, 2004), pp. 545-547.

[13] A. Fabich and C. Hessler, Technical Report, HiRadMat Project No. 2010-02, CERN, Geneva, 2010.

[14] D. Deboy, O. Aberle, R. Assmann, F. Carra, M. Cauchi, J. Lendaro, A. Masi, and S. Redaelli, in Proceedings of the 4th International Particle Accelerator Conference, Shanghai, China, 2013 (to be published).

[15] F. Carra, A. Bertarelli, A. Dallocchio, L. Lari, and M. Mariani, "Expected Damage on TCTA Collimator during HRMT09-LCOL Experiment in HiRadMat Facility," in the Collimation Working Group at CERN, 2012.

[16] A. Bertarelli, R. Bruce, F. Carra, A. Dallocchio, M. Guinchard, M. Mariani, L. Lari, S. Redaelli, and A. Rossi, in Proceedings of the LHC Machine Protection Workshop, Annecy, France, 2013 (to be published).

[17] A. Dallocchio, Ph.D. thesis, Polytechnic University of Turin, Turin, 2008. 
[18] $\operatorname{ANSYS}^{\circledR}$ Mechanical, Academic Research, Release 12.1, Help System, Workbench User's Guide, ANSYS, Inc., 2009.

[19] ANSYS $^{\circledR}$ Autodyn, Release 13.0, Help System, User Manual, ANSYS, Inc., 2010.

[20] A. Ferrari, P. R. Sala, A. Fasso, and J. Ranft, FLUKA: A Multi-particle Transport Code (program version 2005) (CERN, Geneva, 2005).

[21] G. Battistoni, F. Cerutti, A. Fasso, A. Ferrari, S. Muraroi, J. Ranft, S. Roesler, and P. Sala, AIP Conf. Proc. 896, 31 (2007).

[22] M. Scapin, L. Peroni, V. Boccone, and F. Cerutti, in Proceedings of 5th International Conference on Computational Methods for Coupled Problems in Science and Engineering, COUPLED PROBLEMS 2013, Ibiza, Spain, 2013.

[23] N. Tahir, J. Blanco Sancho, A. Shutov, R. Schmidt, and A. Piriz, Phys. Rev. ST Accel. Beams 15, 051003 (2012).
[24] M. Scapin, L. Peroni, and A. Dallocchio, J. Nucl. Mater. 420, 463 (2012).

[25] W. Kalbreier, W. Middelkoop, and P. Sievers, Technical Report No. CERN-Lab-2-BT-74-1, CERN, Geneva, 1974.

[26] M. Cauchi and W. Hohenauer, Technical Report No. CERN-ACC-NOTE-2013-0023, Austrian Institute of Technology, Austria, and CERN, Geneva, Switzerland, 2013.

[27] A. Bertarelli, F. Carra, F. Cerutti, A. Dallocchio, M. Garlasche, M. Guinchard, N. Mariani, S. D. M. dos Santos, L. Peroni, M. Scapin, and V. Boccone, J. Phys. Conf. Ser. 451, 012005 (2013).

[28] S. P. Lyon and J. D. Johnson, Report No. LA-UR-92-3407, 1992.

[29] M. van Thiel, Lawrence Livermore Laboratory Report No. UCRL-50108, Rev. 1, 1977. 